\title{
STEADY - STATE PERFORMANCE OF INDUCTION AND TRANSFER FIELD MOTORS - A COMPARISON
}

\author{
L. U. Anih ${ }^{1,}$, E. S. Obe ${ }^{2}$ and M. N. Eleanya ${ }^{3}$ \\ 1,2 DePARTMENT OF ELECTRICAL ENGINEERING, UNIVERSITY OF NIGERIA, NSUKKA, NIGERIA \\ 3 DePARTMENT OF ELECTRICAL ENGINEERING, NNAMdi AZIKIWE UNIVERSITY, AWKA, NIGERIA \\ E-mail addresses:1 linus.anih@unn.edu.ng, 2 simon.obe@unn.edu.ng,3eleanyamichael@yahoo.com
}

\begin{abstract}
This paper presents the steady-state performance comparison between polyphase induction motor and polyphase TF motor operating in the asynchronous mode. It is shown graphically that a p-pole TF motor in operation is similar to an induction motor with $2 p$ poles and hence its synchronous speed is limited to one-half $(\omega / 2)$ of that of an induction motor. Additionally the pull-out torque of TF motor is inferior to that of an induction motor of the same dimensions, being less than $1 / 4$ of that of an equivalent induction motor on account of its higher leakage reactance and in particular, the quadrature axis reactance.
\end{abstract}

Keywords: Steady - state, pull-out torque, half-speed, asynchronous mode, induction motor, transfer-field motor

\section{INTRODUCTION}

Induction motors are widely used as a means of converting electrical power to mechanical work and have been variously described as the "work horse" of the industry. They constitute the largest group of motors used in the industries as over $90 \%$ of all industrial motors are induction motors. In its normal working range the speed of the induction motor remains substantially constant, varying only slightly with load. In view of the wide use of induction motors, the performance characteristics are well known and adequately covered in literature.

TF machine on the other hand made its debut to the family of rotating electrical machines in 1978 and occupies a very lowly position in the family. Its existence and precise characteristics are not too wellknown because of its relative inferior characteristics when compared to an induction motor of the same dimensions. Furthermore, the power factor is low and generally below 0.5 because of the high magnetizing current of the machine. In spite of these disadvantages, TF machines have found applications in such areas as in control, electrical gear, low speed drives etc [1] and have the potential of replacing induction motors if the output power can be enhanced [2].
Despite the enormous difference in the physical configurations and mechanism of torque development in the two machines, both machines display similar torque-speed characteristics which suggests that close parallels must exist between the two machines. This paper undertakes a comparative study between the two machines with a view to finding out the close parallels between them. In the comparison, more efforts were devoted in deriving the performance indices of the TF machine and this is predicated on limited available literature on the machine.

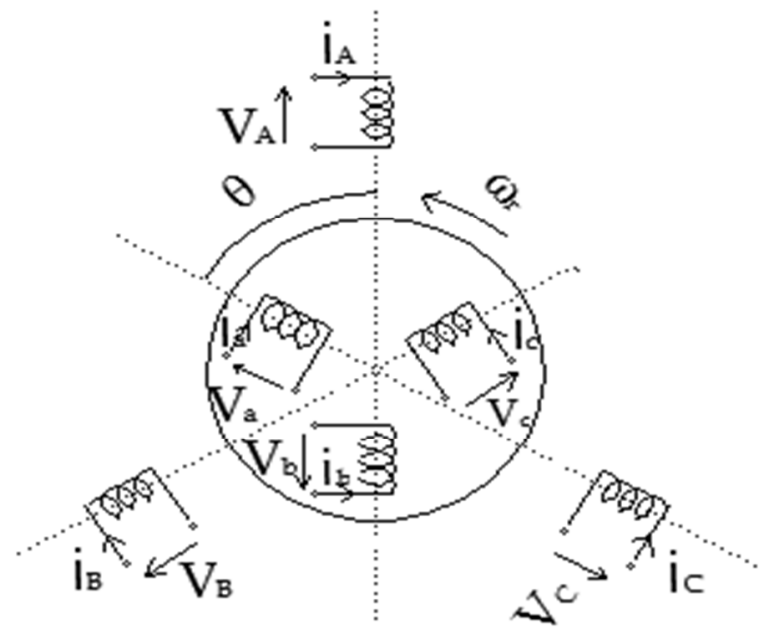

Fig 1: Cross-section of a 2-pole 3-phase induction motor. 


\section{PHYSICAL CONFIGURATION}

\subsection{Polyphase induction motor}

A conventional induction motor comprises a stator and a rotor mounted on bearings and separated from the stator by a small air-gap. The stator consists of a magnetic core made up of laminations carrying slotembedded conductors. These conductors are interconnected in a pre-determined manner and constitute the stator/primary windings. The rotor is cylindrical and carries either conducting bars shortcircuited at both ends by end rings (squirrel cage rotor) or a polyphase winding (secondary) connected also in a pre-determined manner and with its terminals brought out to slip rings for external connections and short-circuited. A cross section of a cylindrical rotor induction motor is as shown in Figure 1 where upper case letters refer to the stator windings while lower case letters refer to the rotor windings. The connection of the windings is shown in Figure $2 \mathrm{~b}$.

\subsection{Polyphase TF machines physical configuration}

The machine in appearance is similar to the conventional salient-pole synchronous machine. The major unorthodox features of the machine are:

(i) The stator and rotor are arranged in two identical coupled halves;

(ii) There are no conductors on the rotor including squirrel cage or damper windings

(iii) The pole axis of the two rotor halves are mutually in space quadrature and mechanically coupled together.

(iv) There is a second set of identical polyphase stator (auxiliary/secondary) windings whose conductor sides are shifted 180 electrical degrees (transposed) in passing from one-half of the machine into the other. Both sets of the winding (main and auxiliary) are distributed in the stator slots such that identical phases occupy the same slot positions for maximum coupling and wound for the same number of poles as the rotor poles.

Like induction motor, the rotors of the coupled halves are mounted on bearings and separated from their stators by small air gaps. Either set of the windings may be connected to the utility supply while the other winding is short-circuited as in induction motors. A cross-section of a polyphase TF machine is as shown in Figure 2a while the interconnection of the windings is shown in Figure $2 b$.

\section{FREQUENCY OF SECONDARY WINDING INDUCED VOLTAGE AND CURRENT OF THE POLYPHASE TF MACHINE}

The main winding is connected to the supply voltage $\mathrm{V}$ and draws a magnetizing current $I_{0}$ at the source frequency $\omega$. This magnetizing current produces a sinusoidally distributed $\mathrm{mmf}$ on both halves of the machine, which may be expressed as:

$m_{o}=M_{o} \cos (\theta-\omega t)$

The air-gap rotor permeance distribution in one section of the machine say unit A, may be expressed as:

$P_{A}=P_{o}+P_{V} \cos 2\left(\theta-\omega_{r} t\right)$

where $\omega_{r}$ is the rotor speed

The flux density, $\mathrm{B}_{\mathrm{A}}$, produced in the air-gap of this machine half is given by the product of (1) and (2) as [3]:

$B_{A}=M_{o} P_{o} \cos (\theta-\omega t)+M_{o} P_{V} \cos (\theta+$

$\left.\left(\omega-2 \omega_{r}\right) t\right)+$ third space harmonics

The air-gap rotor permeance distribution in section $\mathrm{B}$ say, whose pole-axis is 90 electrical degrees phase displaced from machine A may be expressed as:

$$
\begin{array}{r}
P_{B}=P_{o}+P_{V} \cos 2\left(\theta-\omega_{r} t-\pi / 2\right) \\
=P_{o}-P_{V} \cos 2\left(\theta-\omega_{r} t\right)
\end{array}
$$

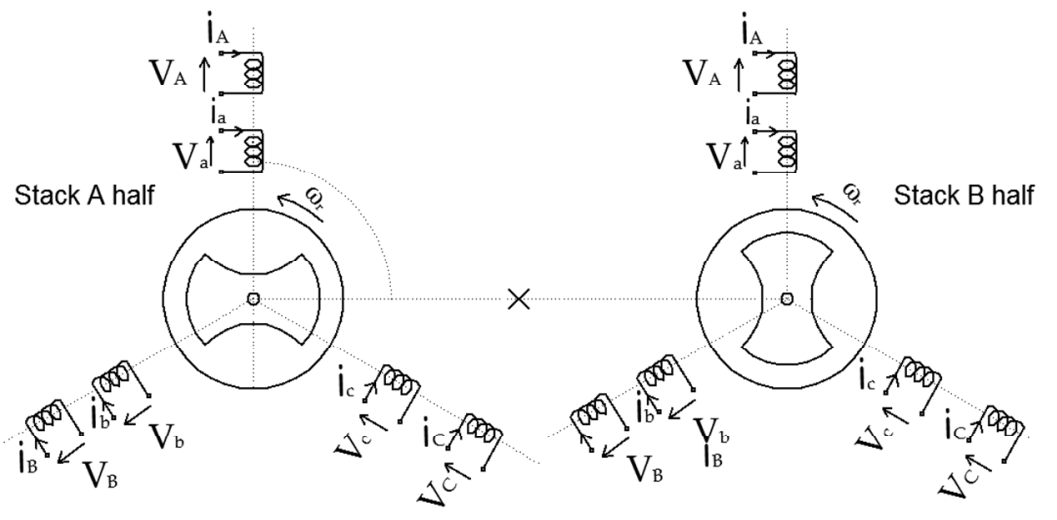

(a)

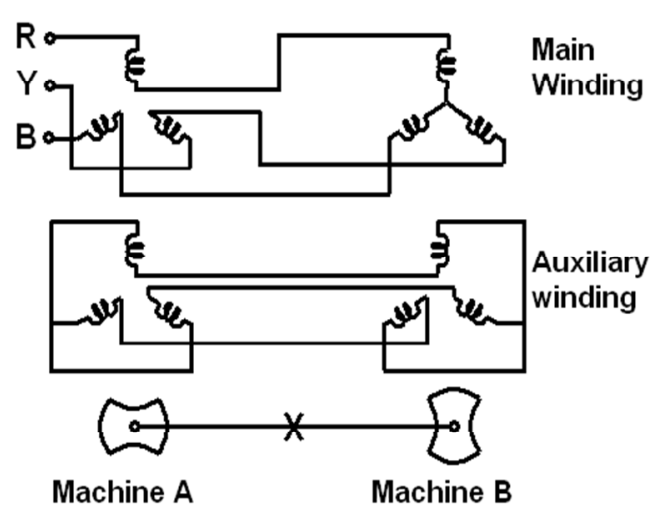

(b)

Figure 2: (a) Cross-section of a 2-pole 3-phase transfer-field machine. Upper case letters refer to main windings while lower case letters refer to auxiliary windings, (b) Connection diagram 


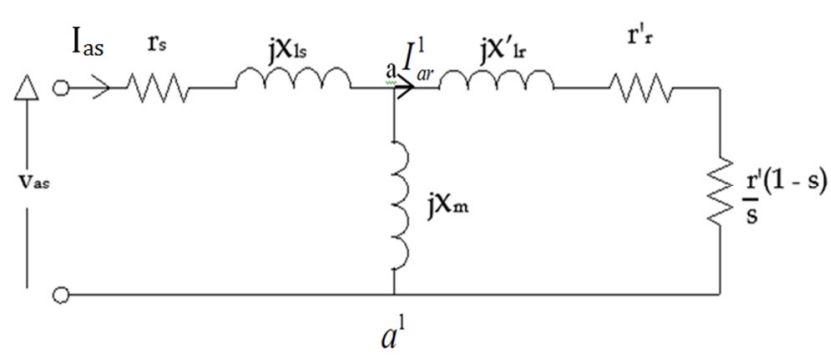

Figure 3: Per phase steady-state equivalent circuit of an induction motor

The flux density $B_{\text {В }}$ produced in this machine half is similarly given by

$$
\begin{aligned}
B_{B}=M_{o} P_{o} \cos & (\theta-\omega t) \\
& -M_{o} P_{V} \cos \left(\theta+\left(\omega-2 \omega_{r}\right) t\right) \\
& + \text { third space harmonics }
\end{aligned}
$$

The third space harmonics in both halves of the machine are eliminated if the windings are starconnected. The average flux density linking the main windings which are connected in series is given by:

$B_{p}=B_{A}+B_{B}=M_{o} P_{o} \cos (\theta-\omega t)$

The average flux density as seen by the auxiliary windings which are connected in anti-series is given by:

$B_{S}=B_{A}-B_{B}=M_{o} P_{V} \cos \left(\theta+\left(\omega-2 \omega_{r}\right) t\right)=$

$M_{o} P_{V} \cos (\theta+(2 s-1) \omega t)$

where $s=\frac{\omega-\omega_{r}}{\omega}$

The field expressed by (7) will induce in the auxiliary windings emf of angular frequency $\left(\omega-2 \omega_{r}\right)$ and whose magnitude is also proportional to $\left(\omega-2 \omega_{r}\right)$ and may be expressed as:

$$
\begin{aligned}
e_{s} & =\mathrm{k}_{\mathrm{a}}\left(\omega-2 \omega_{\mathrm{r}}\right) \sin \left(\omega-2 \omega_{\mathrm{r}}\right) \mathrm{t} \\
& =\mathrm{k}_{\mathrm{a}}(2 \mathrm{~s}-1) \omega \sin (2 \mathrm{~s}-1) \omega \mathrm{t}
\end{aligned}
$$

The field expressed by (6) will induce in the main winding, emf of angular frequency $\omega$ and may be expressed as:

$e_{p}=\mathrm{k}_{\mathrm{a}} \omega \sin \omega \mathrm{t}$

where $\mathrm{k}_{\mathrm{a}}$ is a proportionality constant.

Consequently, the ratio of the angular frequencies of voltage induced in the main and auxiliary windings of a TF machine is thus $\omega:(2 s-1) \omega$.

Similarly, the voltages induced in the rotor and stator windings of an induction motor are given respectively as:

$e_{r}=\mathrm{k}_{\mathrm{b}}\left(\omega-\omega_{\mathrm{r}}\right) \sin \left(\omega-\omega_{\mathrm{r}}\right) \mathrm{t}=\mathrm{k}_{\mathrm{b}} \mathrm{s} \omega \sin (\mathrm{s} \omega) \mathrm{t}$ and

$e_{s}=\mathrm{k}_{\mathrm{b}} \omega \sin (\omega \mathrm{t})$

where $\mathrm{k}_{\mathrm{b}}$ is a constant of proportionality.

Consequently, the ratio of angular frequencies of the voltage induced in the stator and rotor of an induction motor is: $\omega: \mathrm{s} \omega$.

The frequency of the voltage induced in the auxiliary winding $\left(\omega-2 \omega_{r}\right)$ is of the nature of the relationship between the frequency of rotor induced voltage and rotor speed in a conventional induction machine $(\omega-$ $\left.\omega_{r}\right)$. The only difference is that the synchronous speed is now $\omega / 2$ instead of $\omega$ in a conventional induction machine.

\section{DYNAMIC MODEL}

\subsection{The induction motor}

The dynamic model of induction motor is well known [8] and it is not repeated here. We will only present the steady-state equivalent circuit shown in Figure 3.

The steady-state electromagnetic torque obtained by considering the power dissipated in the slip dependent resistance of Figure 3 is given by:

$$
T=\frac{3\left|I_{a r}^{\prime}{ }^{2} r_{r}^{\prime} / s\right|}{\omega} \quad(N-m)
$$

The efficiency of the machine neglecting core loss can be shown to be:

$$
\eta=\frac{I_{a r}^{\prime 2} r_{r}^{\prime}(1-s) / s}{I_{a r}^{\prime 2} r_{r}^{\prime}(1-s) / s+I_{a s}^{2} r_{s}+I_{a r}^{2} r_{r}^{\prime}}
$$

\subsection{The dynamic model of a TF motor}

The voltage equations for the main and auxiliary windings of the three-phase machine are:

$V_{A B C}=r_{A B C} i_{A B C}+p \lambda_{A B C}$

$V_{a b c}=r_{a b c} i_{a b c}+p \lambda_{a b c}$

Upper case subscripts refer to the main winding parameters while lower case subscripts refer to auxiliary windings.

The flux linkages of the main and auxiliary windings may be expressed as:

$\left[\begin{array}{l}\lambda_{A B C} \\ \lambda_{a b c}\end{array}\right]=\left[\begin{array}{ll}L_{G G} & L_{G H} \\ L_{H G} & L_{H H}\end{array}\right]\left[\begin{array}{l}i_{A B C} \\ i_{a b c}\end{array}\right]$

The inductance matrix terms $\mathrm{L}_{\mathrm{GG}}, \mathrm{L}_{\mathrm{GH}}, \mathrm{L}_{\mathrm{HG}}$, and $\mathrm{L}_{\mathrm{HH}}$ are obtained from the inductance submatrices $\mathrm{L}_{11}, \mathrm{~L}_{12}, \mathrm{~L}_{21}$, and $L_{22}$ for machines $A$ and $B$. In view of the similarity of the primary and secondary windings (i.e. main and auxiliary windings):

$L_{H H}=L_{G G}=L_{11 \text { machine } A}+L_{11 \text { machine } B}$ and

$L_{G H}=L_{H G}=L_{12 \text { machine } A}+L_{21 \text { machine } B}$ where

$L_{11}=\left[\begin{array}{lll}L_{A A} & L_{A B} & L_{A C} \\ L_{B A} & L_{B B} & L_{B C} \\ L_{C A} & L_{C B} & L_{C C}\end{array}\right], L_{12}= \pm\left[\begin{array}{lll}L_{A a} & L_{A b} & L_{A C} \\ L_{B a} & L_{B b} & L_{B C} \\ L_{C a} & L_{C b} & L_{C C}\end{array}\right]$ $L_{21}= \pm\left[\begin{array}{lll}L_{a A} & L_{a B} & L_{a c} \\ L_{b A} & L_{b B} & L_{b C} \\ L_{c A} & L_{c B} & L_{c C}\end{array}\right], \quad L_{22}=\left[\begin{array}{lll}L_{a a} & L_{a b} & L_{a c} \\ L_{b a} & L_{b b} & L_{b c} \\ L_{c a} & L_{c b} & L_{c c}\end{array}\right]$

The \pm in the mutual coupling inductance terms $L_{21}$ and $\mathrm{L}_{12}$ is because of the transposition of the auxiliary winding and in consequence, when the mutual coupling inductance is positive in one-half of the machine, it is negative in the other and vice-versa. 
$L_{11}^{A}=\left[\begin{array}{ccc}L_{l s}+L_{o}-L_{m s} \cos 2 \theta_{r} & -\frac{1}{2} L_{o}-L_{m s} \cos 2\left(\theta_{r}-\pi / 3\right) & -\frac{1}{2} L_{o}-L_{m s} \cos 2\left(\theta_{r}+\pi / 3\right) \\ -\frac{1}{2} L_{o}-L_{m s} \cos 2\left(\theta_{r}-\pi / 3\right) & L_{l s}+L_{o}-L_{m s} \cos 2\left(\theta_{r}+2 \pi / 3\right) & -\frac{1}{2} L_{o}-L_{m s} \cos 2\left(\theta_{r}-\pi\right) \\ -\frac{1}{2} L_{o}-L_{m s} \cos 2\left(\theta_{r}+\pi / 3\right) & -\frac{1}{2} L_{o}-L_{m s} \cos 2\left(\theta_{r}-\pi\right) & L_{l s}+L_{o}-L_{m s} \cos 2\left(\theta_{r}-2 \pi / 3\right)\end{array}\right]$ (17)
$L_{11}^{B}=\left[\begin{array}{ccc}L_{l s}+L_{o}+L_{m s} \cos 2 \theta_{r} & -\frac{1}{2} L_{o}+L_{m s} \cos 2\left(\theta_{r}-\pi / 3\right) & -\frac{1}{2} L_{o}+L_{m s} \cos 2\left(\theta_{r}+\pi / 3\right) \\ -\frac{1}{2} L_{o}+L_{m s} \cos 2\left(\theta_{r}-\pi / 3\right) & L_{l s}+L_{o}+L_{m s} \cos 2\left(\theta_{r}+2 \pi / 3\right) & -\frac{1}{2} L_{o}+L_{m s} \cos 2\left(\theta_{r}-\pi\right) \\ -\frac{1}{2} L_{o}+L_{m s} \cos 2\left(\theta_{r}+\pi / 3\right) & -\frac{1}{2} L_{o}+L_{m s} \cos 2\left(\theta_{r}-\pi\right) & L_{l s}+L_{o}-L_{m s} \cos 2\left(\theta_{r}-2 \pi / 3\right)\end{array}\right](18)$
$L_{G G}=\left[\begin{array}{ccc}2 L_{l s}+2 L_{o} & -L_{o} & -L_{o} \\ -L_{o} & 2 L_{l s}+2 L_{o} & -L_{o} \\ -L_{o} & -L_{o} & 2 L_{l s}+2 L_{o}\end{array}\right]$
$=\left[\begin{array}{ccc}2 L_{l s}+L_{m d}+L_{m q} & -\frac{1}{2}\left(L_{m d}+L_{m q}\right) & -\frac{1}{2}\left(L_{m d}+L_{m q}\right) \\ -\frac{1}{2}\left(L_{m d}+L_{m q}\right) & 2 L_{l s}+L_{m d}+L_{m q} & -\frac{1}{2}\left(L_{m d}+L_{m q}\right) \\ -\frac{1}{2}\left(L_{m d}+L_{m q}\right) & -\frac{1}{2}\left(L_{m d}+L_{m q}\right) & 2 L_{l s}+L_{m d}+L_{m q}\end{array}\right]$

where

$$
L_{o}=\frac{L_{m d}+L_{m q}}{2}
$$

$\operatorname{and} L_{m s}=\frac{L_{m d}-L_{m q}}{2}$

Similarly:

$L_{G H}=L_{12}^{A}+L_{12}^{B}=\left(L_{m q}-L_{m d}\right)\left[\begin{array}{ccc}\cos 2 \theta_{r} & \cos 2\left(\theta_{r}-\frac{\pi}{3}\right) & \cos 2\left(\theta_{r}+\frac{\pi}{3}\right) \\ \cos 2\left(\theta_{r}-\frac{\pi}{3}\right) & \cos 2\left(\theta_{r}+\frac{\pi}{3}\right) & \cos 2 \theta_{r} \\ \cos 2\left(\theta_{r}+\frac{\pi}{3}\right) & \cos 2 \theta_{r} & \cos 2\left(\theta_{r}-\frac{\pi}{3}\right)\end{array}\right]$

Since the main and auxiliary windings are identical in all respects including number of turns, auxiliary winding parameters retain the same values when referred to the main windings and vice-versa.

$\mathrm{L}_{\mathrm{GG}}=\mathrm{L}_{\mathrm{HH}}$ and $\mathrm{L}_{\mathrm{GH}}=\mathrm{L}_{\mathrm{HG}}$

Equation 14 re-written in arbitrary D - Q - O reference frame is given by:

$$
\left[\begin{array}{l}
\lambda_{Q D O} \\
\lambda_{q d o}
\end{array}\right]=\left[\begin{array}{ll}
k_{G} L_{G G}\left(k_{G}\right)^{-1} & k_{G} L_{G H}\left(k_{H}\right)^{-1} \\
k_{H}\left(L_{G H}\right)^{T}\left(k_{G}\right)^{-1} & k_{H} L_{H H}\left(k_{H}\right)^{-1}
\end{array}\right]\left[\begin{array}{l}
I_{Q D O} \\
I_{q d o}
\end{array}\right]
$$

where

$$
\begin{gathered}
k_{G}=\frac{2}{3}\left[\begin{array}{ccc}
\cos \theta & \cos (\theta-2 \pi / 3) & \cos (\theta+2 \pi / 3) \\
\sin \theta & \sin (\theta-2 \pi / 3) & \sin (\theta+2 \pi / 3) \\
1 / 2 & 1 / 2 & 1 / 2
\end{array}\right] \\
\text { and } k_{H}=\frac{2}{3}\left[\begin{array}{ccc}
\cos \beta & \cos (\beta-2 \pi / 3) & \cos (\beta+2 \pi / 3) \\
\sin \beta & \sin (\beta-2 \pi / 3) & \sin (\beta+2 \pi / 3) \\
1 / 2 & 1 / 2 & 1 / 2
\end{array}\right] \\
\beta=\left(\theta-2 \theta_{r}\right)
\end{gathered}
$$

The $\mathrm{D}-\mathrm{Q}-\mathrm{O}$ voltage equations of the TF machine in expanded form gives

$V_{Q}=2 r i_{Q}+\omega \lambda_{D}+p \lambda_{Q}$

$V_{D}=2 r i_{D}-\omega \lambda_{Q}+p \lambda_{D}$

$V_{0}=2 r i_{0}+p \lambda_{0}$

$$
\begin{aligned}
& V_{q}=2 r i_{q}-\left(\omega-2 \omega_{r}\right) \lambda_{d}+p \lambda_{q} \\
& V_{d}=2 r i_{d}+\left(\omega-2 \omega_{r}\right) \lambda_{q}+p \lambda_{d} \\
& V_{0}=2 r i_{0}+p \lambda_{0}
\end{aligned}
$$

where the flux linkages is expressed as:

$$
\begin{aligned}
& \lambda_{Q}=\left(2 L_{L}+L_{m q}+L_{m d}\right) I_{Q}-\left(L_{m d}-L_{m q}\right) I_{q} \\
& \lambda_{D}=\left(2 L_{L}+L_{m q}+L_{m d}\right) I_{D}+\left(L_{m d}-L_{m q}\right) I_{d} \\
& \lambda_{0}=2 L_{L} I_{0} \\
& \lambda_{q}=\left(2 L_{L}+L_{m q}+L_{m d}\right) I_{q}-\left(L_{m d}-L_{m q}\right) I_{Q} \\
& \lambda_{d}=\left(2 L_{L}+L_{m q}+L_{m d}\right) I_{d}+\left(L_{m d}-L_{m q}\right) I_{D} \\
& \lambda_{0}=2 L_{L} I_{0}
\end{aligned}
$$

$2 \mathrm{r}$ is the sum of the resistances of the main or auxiliary windings in both halves of the machine. The voltage and flux linkage equations suggest the dynamic equivalent circuit shown in Fig 4 while Fig 5 shows the steady-state equivalent circuit of TF machine derived analogously to that of induction machine by assuming that the q-axis is aligned to phase $A$ of the $A B C$ system with all the derivative terms set to zero.

The expression for electromagnetic torque obtained from the energy stored in the coupling field is expressed analogously to that of an induction motor as: 


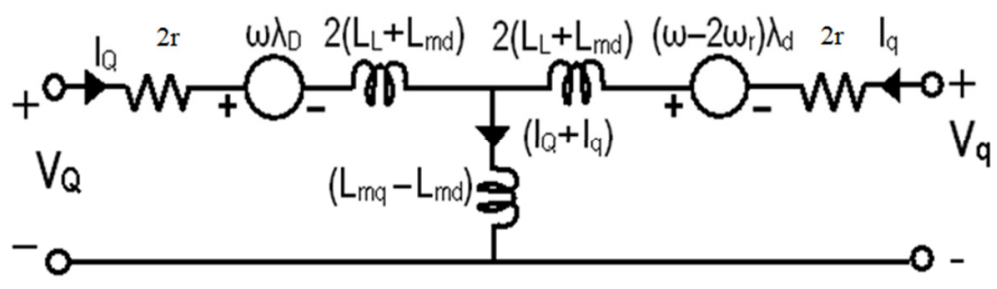

(a) q-axis

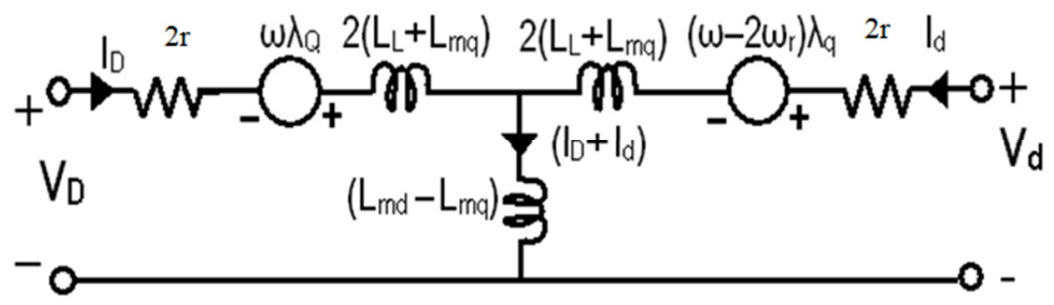

(b) d-axis

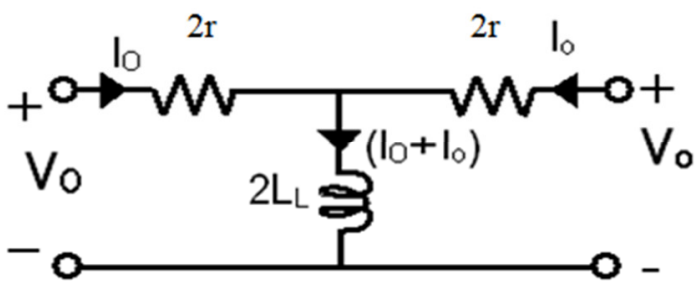

(c) $o$-axis

Figure 4: Dynamic equivalent circuits of the TF machine in arbitrary reference frame

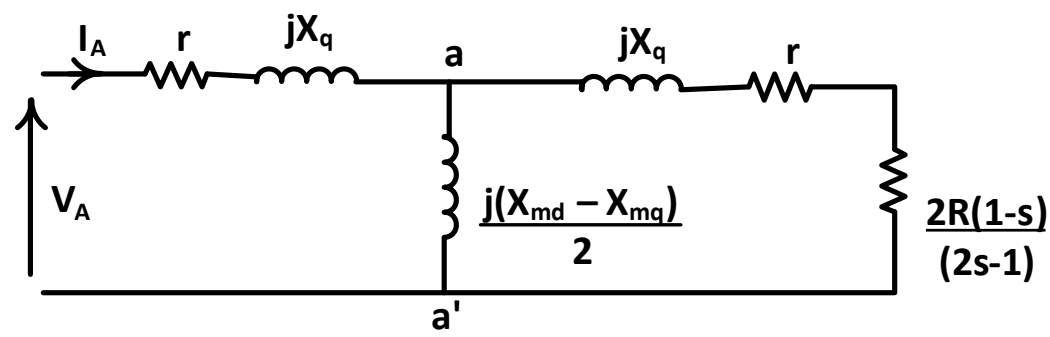

Figure 5: per phase steady-state equivalent circuit of a TF machine

$T_{e}=\frac{P}{2}\left(i_{A B C}\right)^{T} \frac{\partial\left[L_{s r}\right]}{\partial \theta} i_{a b c}$

$=\left(\frac{P}{2}\right)\left[\left(k_{G}\right)^{-1} i_{Q D 0}\right]^{T} \frac{\partial}{\partial \theta_{r}}\left[L_{s r}\right]\left(k_{H}\right)^{-1} i_{q d 0} N m$

This expression yields the torque expressed in terms of current as [6]:

$T_{e}=\left(\frac{3}{2}\right)\left(\frac{P}{2}\right)\left(L_{m d}-L_{m q}\right)\left(I_{Q} I_{d}+I_{q} I_{D}\right) N m$

The steady-state torque with reference to Fig 5 is calculated on the basis of power dissipated in the slip dependent resistance as:

$T_{e}=\frac{6\left|I_{a}\right|^{2} r}{\omega(2 s-1)} \quad \mathrm{Nm}$

The efficiency of a TF machine neglecting core loss can be shown to be:

$\eta=\frac{2 r I_{a}^{2}(1-s) /(2 s-1)}{2 r I_{a}^{2}(1-s) /(2 s-1)+I_{A}^{2} r+I_{a}^{2} r}$
Equation (20) represents the inductance matrix of the main and auxiliary windings respectively of the TF machine because of the similarity of the windings and seen to be independent of the rotor angular position; while (23) represents the mutual inductance between the main and auxiliary windings, which is seen to be a function of the cyclic variation of the rotor angular position. Both (20) and (23) are similar to the inductance expressions for wound rotor induction motors, even though the individual halves constituting the $\mathrm{TF}$ machine possess salient rotors without rotor conductors.

Although the mutual inductance of a TF machine depends on the cyclic variation of the rotor angular position, it also depends on the difference between the $\mathrm{d}$-axis and q-axis inductances (i.e. reluctance). Consequently, the nature of torque of TF machine is reluctance torque. Classically, TF machine may be 
analysed as two reluctance machines connected in cascade. In contrast to this, the torque of an induction motor is by the too well known alignment of fields principle.

\section{OUTPUT TORQUE}

From Fig 5, it can be readily shown that the voltage induced in the auxiliary winding of a TF machine when it is on open circuit i.e. the voltage across $\mathrm{aa}^{1}$ is proportional to the transfer ratio $c$, which may be expressed as:

$c=\frac{x_{m d}-x_{m q}}{x_{m q}+x_{m d}+2 x_{L s}}$

$=\frac{k-1}{k+1+2 \sigma}$

if $\left(x_{m q}+x_{m d}+2 x_{l s}\right) \gg 2 r$

where

$k=\frac{x_{m d}}{x_{m q}}, \sigma=\frac{x_{l s}}{x_{m q}}$, and $\mathrm{x}_{\mathrm{q}}=\mathrm{x}_{\mathrm{mq}}+\mathrm{x}_{\mathrm{ls}}$

The ratio c would compare very unfavourably with the equivalent ratio for a conventional induction motor (as shown in Fig 3) which may similarly be expressed as:

$$
\begin{aligned}
c^{\prime} & =\frac{x_{m}}{x_{m}+x_{L s}} \\
& =\frac{1}{1+\beta \sigma}
\end{aligned}
$$

if $\left(\mathrm{x}_{\mathrm{m}}+\mathrm{x}_{I s}\right)>>\mathrm{r}_{\mathrm{s}} \quad$ where $\beta=\frac{x_{m q}}{x_{m}}$

Reference [7] derived values of $c$ and $c^{\prime}$ as 0.42 and 0.98 respectively using typical values of $\sigma$ and $\beta$.

The transfer factors $c$ and $c^{\prime}$ determines the magnitude of the induced emf in the secondary windings and consequently determines the current and torque.

Suppose the secondary winding impedance of the TF machine is of the same magnitude as that of an induction motor with which it is being compared, its secondary current will be less than $1 / 2$ of that of an induction motor and the torque which is directly proportional to the square of the current will be less than $1 / 4$ of the equivalent induction motor. The situation is further aggravated by the fact that leakage reactance of the secondary windings of TF machine is greater than that of a conventional induction motor since it comprises the normal leakage inductance as in induction motor plus the quadrature axis inductance.

Consequently, the secondary current of the TF machine will be considerably less than $1 / 2$ of the normal equivalent induction motor and the torque less than $1 / 4$ of the normal equivalent induction motor torque.

\subsection{Torque Speed Characteristics and Efficiency}

The magnitude of the emf induced in the auxiliary winding is proportional to the velocity $\left(\omega-2 \omega_{\mathrm{r}}\right)$ at which the air-gap flux cuts the auxiliary winding conductors. The auxiliary winding current and hence torque will therefore be zero when $\omega_{\mathrm{r}}=\omega / 2$.

The asynchronous torque/speed characteristic of the machine will resemble that of an induction motor with twice as many stator magnetic poles. In the speed range of $1>\mathrm{s}>0.5$ the machine is motoring and in the range $0.5>s>0$ the machine is generating.

Similarly, the magnitude of the emf induced in the rotor winding of an induction motor is proportional to velocity $\left(\omega-\omega_{r}\right)$ at which the rotor conductors cut the air-gap flux. The rotor winding current and hence torque will be zero when $\omega_{\mathrm{r}}=\omega$. In the speed range of $1>\mathrm{s}>0$, the machine is motoring and in the speed $0>$ $s>-1$, the machine is generating. The torque slip characteristic of induction and comparable TF motors with parameters as shown in Table 1, using (10) and (41) are shown in Figure 6.

A plot of the efficiency against slip using (11) and (42) are shown in Figure 7.

Table 1: Machine Parameters

\begin{tabular}{ccc}
\hline $\begin{array}{c}\text { Machine type } \rightarrow \\
\text { Parameter } \downarrow\end{array}$ & Induction Motor & $\begin{array}{c}\text { TF motor } \\
\text { (Unit Stack) }\end{array}$ \\
\hline $\mathrm{r}(\Omega)$ & 1.10 & 1.10 \\
$\mathrm{X}_{\mathrm{L}}(\Omega)$ & 1.82 & 1.82 \\
$\mathrm{X}_{\mathrm{md}}(\Omega)$ & - & 19 \\
$\mathrm{X}_{\mathrm{mq}}(\Omega)$ & - & 6 \\
$\mathrm{X}(\Omega)$ & 36 & 6.5 \\
$\mathrm{~V}(\mathrm{~V})$ & 240 & 120 \\
\hline
\end{tabular}

Since the stator windings of the TF machine are connected in series, the voltage applied to a unit half of TF machine is one-half of that applied to the comparative induction motor.

\section{CONCLUSION}

Comparison between the performance characteristics of a TF machine and induction motor has been presented.

TF machine operating in the asynchronous mode is essentially an induction motor with twice its magnetic poles which limits its synchronous speed to one-half of that of an equivalent Induction motor. Although, all the windings of TF machine are located on the stator side, the auxiliary windings play the role of the rotor winding of an induction motor while being stationary and this is an advantage, from control point of view. Insight into the similarity of the torque - slip characteristics of Induction and TF motors may be gained when the two - halves comprising the TF machine whose salient - pole rotors are in space quadrature are superimposed. 


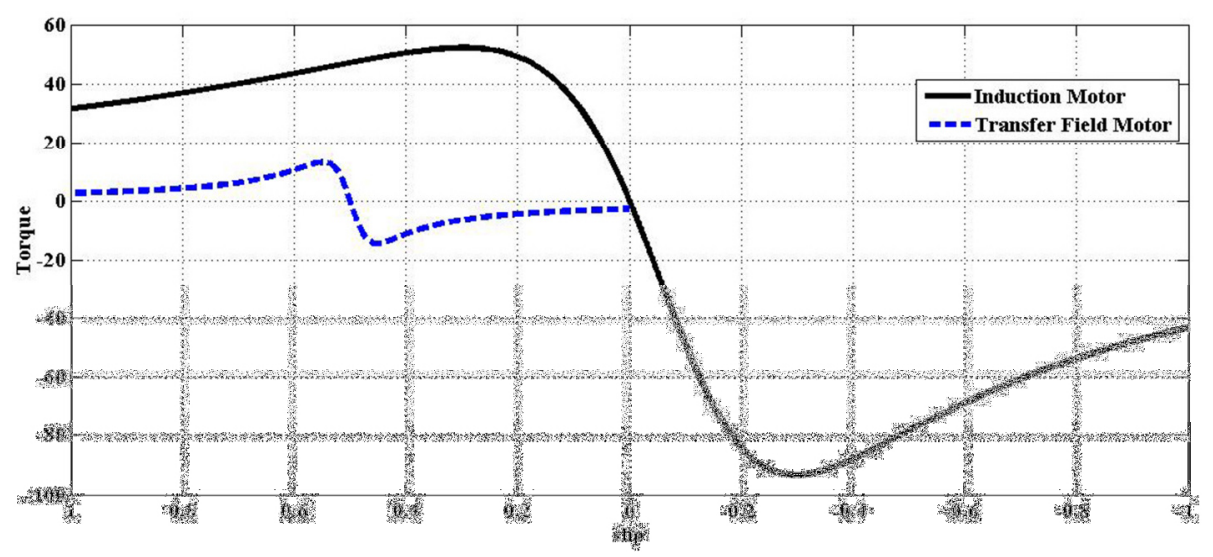

Figure 6: Steady-State torque slip characteristics of IM and TF motor

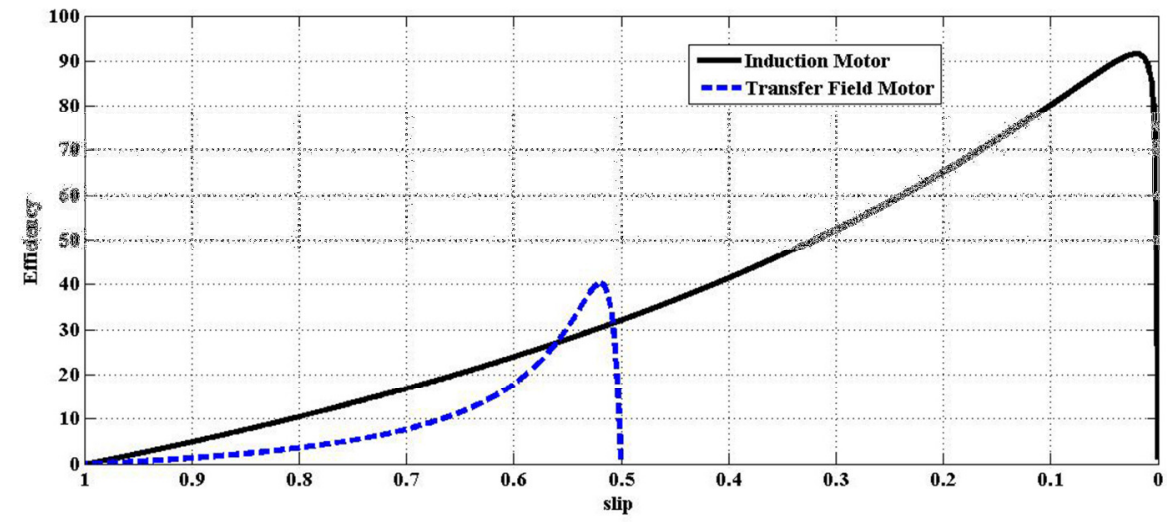

Figure 7: Efficiency versus slip

The superimposition makes it obvious to observe that the two - halves constitute a round rotor machine similar to an induction motor. Consequently, the inductance distributions of $\mathrm{TF}$ machine resemble those of an Induction machine and hence similar torque - slip characteristic.

The pull-out and starting torque of TF machine are inferior to those of a comparable induction motor. The low starting torque is attributed to the high ratio of effective secondary leakage reactance to effective secondary resistance. In induction motors, the starting torque increases as this ratio decreases. The low pullout torque is due to the high leakage reactance in comparison with a conventional induction motor. The leakage reactance of the machine set is the sum of the normal leakage reactance and the quadrature axis reactance.

Deeper slots of the stator to accommodate the two sets of main and auxiliary windings also enhance leakage reactance. Both machines are capable of synchronous mode operation if dc field excitation is applied to their secondary windings when their rotors are brought to their respective synchronous speeds. Enhancement of the output power of TF machine is being studied by the authors.

\section{REFERENCES}

[1] L. A. Agu, "The transfer-field electric machine", Electric Machine and Electromechanics, Vol 2, No 4, 1978 pp $403-418$.

[2] J. J. Cathey and S. A. Nasar, "Equivalent circuit of Transfer Field Machine for Asynchronous mode of operation", Electrical Machines and Electromechanics, 6, 1981, pp $307-321$.

[3] P. J. Lawrenson and L. A. Agu "Theory and Performance of polyphase reluctance machines," Pro. Inst. Elec. Eng.(London), Vol. 111, pp. 1435 - 1445, August 1964.

[4] P. C. Krause, O. Wasynczuk and S. D. Sudhoff Analysis of Electric Machinery, Mc Graw-Hill New York 1986.

[5] K.P. Kovacs, “On asymmetrical rotor induction machines" (in German), Arch Fur Electrotech., vol 49 No 3, pp 190 - 202, 1965.

[6] L. U. Anih and E. S. Obe, "Performance analysis of a composite dual winding reluctance machine". Energy Conversion and Management 50, 2009, pp 3056 3062.

[7] L. A. Agu "Output Power enhancement in the Transfer - Field machine using rotor circuit induced currents" Nigerian Journal of Technology, Vol 8, 1984, pp 7 - 14. 